Article

\title{
Exploring the Role of Public-Private Partnerships in Forest Protection
}

\author{
Ulrika Widman \\ Department of Political Science, Umeå University, Umeå 901 87, Sweden; ulrika.widman@umu.se; \\ Tel.: +46-90-786-63-76
}

Academic Editor: Vincenzo Torretta

Received: 22 February 2016; Accepted: 17 May 2016; Published: 20 May 2016

\begin{abstract}
In 2010, the Swedish government established the Komet program-a pilot forest protection project that was initially implemented in five land areas. The Komet program was intended to complement existing formal protection measures by establishing partnerships with forest owners and industries to encourage these actors to take a greater interest in contributing to forest conservation efforts and Nature Conservation Agreements. Despite mixed results, the government subsequently chose to implement these partnerships nationwide, thereby institutionalizing the Komet program and making it into a regular component of forest management policy. This study examines how the program developed and became institutionalized. The theoretical role of public-private partnerships and their capacity to deliver collective goods are discussed. The empirical material primarily consists of interviews with key stakeholders from the pilot period and the present reference group. The results highlight the need to carefully consider past collaborative experiences together with existing motives relating to the role of partnerships in forest protection in order to achieve successful institutionalization. This will increase the government's capacity to create the conditions for institutionalization and may facilitate the development of external interactions in partnerships, leading to the incorporation of various protection arrangements.
\end{abstract}

Keywords: public-private partnerships; forest protection; collaboration; institutionalization

\section{Introduction}

Like many other countries around the world, Sweden has encountered significant difficulties in its attempts to comply with its international commitments relating to the sustainable protection of forests [1]. The government has therefore called for intensified measures targeting (i) forested areas of high stand-level value; (ii) green infrastructure (i.e., areas that, by virtue of their size and location, make important contributions to landscape-level functional networks); and (iii) forest types that Sweden has an international responsibility to preserve [2]. Since privately owned forests represent a relatively large proportion of Sweden's total forested area, like the other Nordic countries, the government has identified cooperation with landowners as a necessary element of forest protection policy [3] although the responsible agencies depart from a national strategy for formal protection where protection of biodiversity values is in focus [4]. However, Swedish landowners initially showed little interest in voluntary protection as the incentives were weak. Similar failures with forest protection in Finland have led to the National Biodiversity Program for Southern Finland (METSO). METSO had a pilot phase from 2002-2007 before becoming fully implemented in 2008, and is now set to continue until 2016 [5]. Inspired by the METSO experience, the Swedish government established the Komet pilot program in five areas of the country to complement existing forest protection measures through financial incentives towards several forms of protection (see Table 1). In total, the productive forest land area in Sweden is $225,000 \mathrm{~km}^{2}$, of which $10 \%$ was included as a part of the Komet program. The Komet program was implemented in 2010-2014, with a national steering committee including representatives from the 
Swedish Environmental Protection Agency (SEPA), the Swedish Forest Agency (SFA), and the County Administrative Board $(\mathrm{CAB})$ from Skåne, the southernmost region. Other key actors with specific competencies were occasionally added to the committee when their expertise was considered valuable. A reference group was also included. The national steering committee determined the rules for the pilot phase, while the reference group was consulted before decision-making, and their advice taken into consideration. In addition, there was a regional working group for each of the five Komet areas, consisting of representatives of the Forest Agency district offices, CABs, forest companies, and forest owners' associations [6].

Table 1. Total number and area of protected forests based on interest applications within the Komet program and outside the program 1 July 2010 to 31 March 2014, for different forms of protection [6].

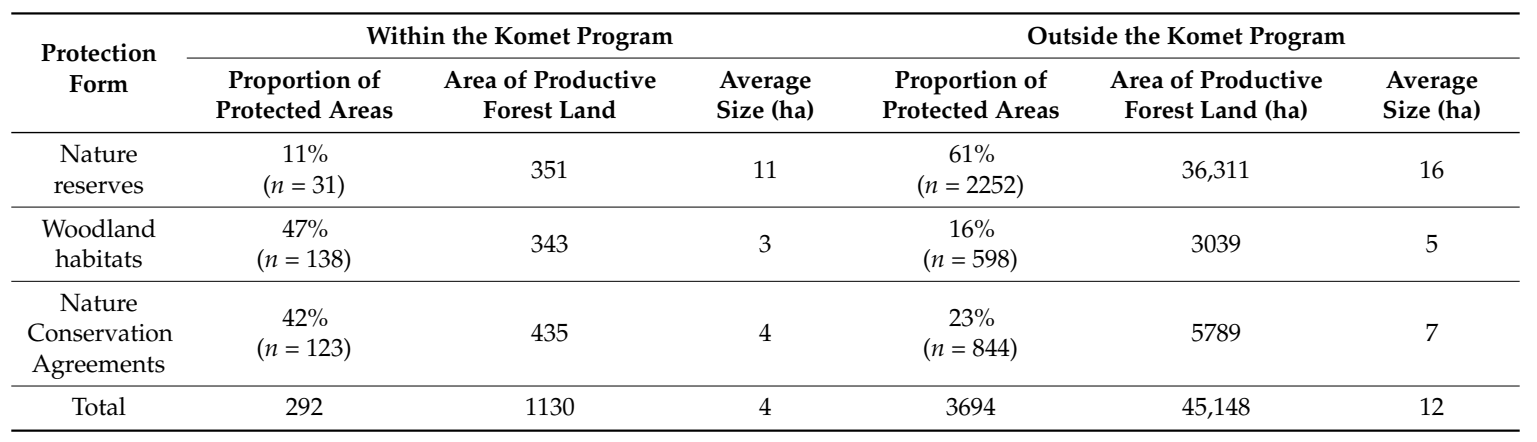

More specifically, the Komet program built on existing partnerships between public agencies and landowners known as Nature Conservation Agreements (NCAs), which were introduced in the mid-1990s. An NCA can be regarded as a form of public-private partnership in which the landowners are compensated for the costs of forest protection activities during a period of negotiated duration. These partnerships are rather top-down in nature, since they must be initiated by governmental authorities. Consequently, landowners have shown relatively little interest in the NCAs. Previous studies also show that the use of regulatory instruments has created conflicts between private landowners and responsible agencies since many owners perceive this as an infringement on private property [5,7]. The Komet program transfers the initiative for forest protection from the state to the individual landowner and was therefore expected to be much more appealing to landowners than the top-down instigated NCAs. The responsible agencies have the final say in the decision-making process, but it is initiated by landowners. Consequently, the proportion of implemented NCAs increased within the program. However, the forms of protection on offer and the payments made to landowners with the voluntary approach are the same as those available with traditional instruments. What is new is the transfer of the initiative for forest protection from the state to the individual landowner and the enhanced role as information advisors that the agencies are given within this national partnership. Private landowners have previously been given the opportunity to participate in forest protection; the implementation of a nationwide partnership is intended to develop these voluntary incentives more 'formally' [6].

However, evaluations of the Komet pilot phase showed mixed results. While some stakeholders, including forest owners' organizations, expressed positive opinions and argued that it had succeeded in changing landowners' views of forest protection [8], nature conservation organizations claimed that the program did not contribute to the fulfilment of governmental forest protection objectives [9]. Despite the mixed results and divided opinions, the Swedish government chose to persevere with the program and extend it across the country, thereby institutionalizing it and making it a regular component of Swedish forest policy [2,6].

The Komet program represents an interesting case both from an empirical and a theoretical perspective. Empirically it allows for the study of how mixed experiences from the pilot phase were taken into account during the institutionalization process. In this case study, we examine theoretical 
questions concerning the institutionalization of public-private partnerships and their capacity to deliver collective goods-in this case, the protection of biodiversity. The concept of partnerships is based on the idea that government (alone) cannot effectively deliver collective goods such as sustainable development and so there is a need to look for support from other sectors of society [10]. While much of the literature on partnerships focuses either on individual partnerships or the initial process of setting up partnerships, there is a lack of research on the mechanisms of institutionalization, here understood as the potential to create a framework of regulations to support partnering processes and their outcome in terms of sustainable solutions for public issues [11].

The objective of this study is to bridge this gap and explore what is required to turn a contested pilot forest protection program into a fully developed and functional form. As further developed below, we assume that the process is influenced by at least three factors: (a) the key stakeholders' experiences of the pilot project and the way in which these experiences (good and/or bad) are incorporated into the institutionalization process of a new partnership; (b) the key stakeholders' motives for participating in the nationwide implementation of the new partnership; and finally (c) the capacity of various organizations, particularly the government, to create the necessary conditions for the partnership's institutionalization.

\section{Theoretical Framework}

\section{Introduction}

By creating a platform for collaboration between public and private actors, partnerships are expected to advance public goods as well as private interests [12,13]. The Ladder of Partnership Activity, developed by Glasbergen [11] combines interactive aspects with mechanisms for institutionalization related to partnering processes. The Ladder was initially designed to address public-private partnerships on a global level. However, it could also be used for analyzing partnerships at local and national levels because of its focus on "the partnering development processes in terms of the critical issues and key challenges that arise, and which contribute to success or failure to create a new management practice" [11].

As shown in Figure 1, the Ladder of Partnership Activity features a number of levels, each of which represents an activity that contributes to the evolution of a partnership process. The first level corresponds to the exploratory phase preceding the partnership, which is then followed by the partnership's formation, the establishment of rules to guide its implementation, and finally what Glasbergen describes as "changing the political order". This last process involves creating public-private regulations that influence the outcome of societal processes relevant to the solution of public issues. Further, the Ladder is based on three dimensions. The first is the dimension of interactions; in the course of the partnership process, the focus shifts from interactions between the partners (known as internal interactions) to the interactions of the partnership with the external environment (external interactions). The second dimension is that of methodology, which relates to the gradual change in the methods used to move the partnership forwards over time. The third dimension is that of actor versus structure: as the partnership progresses there is a shift in the stakeholders' intentions and their collaborations (in this case, the individual landowners' and authorities) to more permanent impacts on the issue area in which the partnership is active [11].

The process of institutionalizing public private partnerships (i.e., creating a framework of regulations underpinning partnering processes and their outcome) would in our case mean successfully turning the Komet program into an integral part of Sweden's formal system of forest protection. In order to achieve this, it would be necessary to create structures from above to support public-private partnerships for forest protection. However, Glasbergen is somewhat vague about the criteria required to successfully achieve such aims. It seems reasonable to start by assuming that important factors are the degree of mutual dependence between the actors, their past experiences, and their history of interaction [14] including their organizational past $[15,16]$. Particularly relevant factors in this 
case would be the experiences of participants in the pilot phase and how these experiences (good and/or bad) are taken into consideration in the institutionalization process. These experiences may in turn affect the involved stakeholder's motives for supporting the institutionalization of partnering processes $[17,18]$. However, motives for supporting partnering processes may also be based in more profound values or ideologies and related critiques of top-down or bottom-up approaches [19]. Based on the extensive literature on public- private partnerships [20-22], it is also reasonable to assume that the capacity, in particular of the government to create the necessary conditions for the institutionalization of the partnering process, may affect the potential for turning the pilot project into a formal part of the Swedish forest policy. New governance arrangements such as partnerships still have to comply with the existing procedures in which they are embedded [22]. For governments, partnering is appealing if the incorporation of private parties from the market and civil society strengthens the realization of their objectives. However, this requires thinking about the place of partnerships in government policies relating to a specific issue area $[23,24]$. A lack of governmental capacity is often demonstrated by an inability to administer and control policy well [25]. In such situations, variables such as the amount of resources in terms of funding and staff are important [17,26] as well as leadership capacity [26-28]. The efficacy of partnerships can depend on how such differences in resource availability and allocation are managed [26]. Leadership is considered to be a central element of partnership processes [29]. The role of leadership may vary at different levels on the Ladder of Partnership Activity, but we can expect the government to play a particularly important role in certain phases, especially in the institutionalization phase. It is also important for the government to avoid advocating for specific solutions and to show respect for the different viewpoints of the involved stakeholders $[28,30]$.
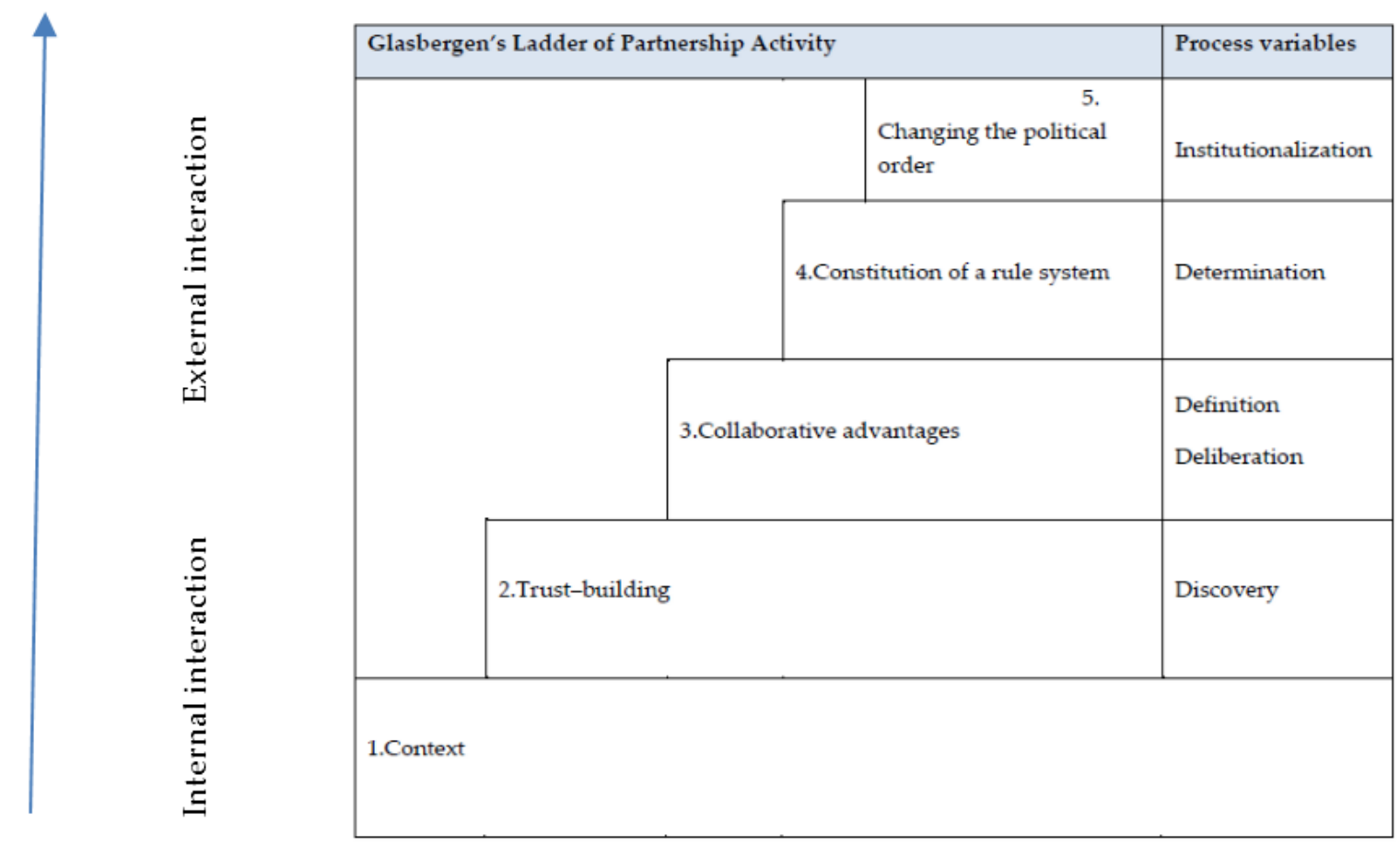

Figure 1. Elaborated version of The Ladder of Partnership Activity $[11,26]$.

To summarize, the institutionalization process is assumed to depend on key stakeholders' past experiences with collaborative efforts but also the government's capacity to create the necessary conditions for partnership institutionalization by supplying the resources and leadership [12,26] needed to achieve the stated objectives. 


\section{Method and Material}

This is an explorative study based on a combination of document studies and interviews. The interviews provided important information, particularly when analyzed together with the written plans and political claims made by the involved key partners [31]. The documents considered include the evaluation of the Komet program, government bills, investigations and guidelines, and statements made by the state agencies: SEPA, SFA, forest owners' associations, Forest Agency district offices, and CABs. In addition, statements found in the referrals made by the involved stakeholders are analyzed The referrals were written by involved partners in the Komet program's steering committee and reference group, and a majority of the CABs and Forest Agency at the regional level.

The main task when analyzing such statements is to identify major differences of opinion between actors and to characterize each of the opinions involved. Even if an actor claims a particular motive in a statement, that may not be helpful in understanding their opinion on the issue [32]. One must also understand how different modes of representation might enable and/or constrain the work of the involved stakeholders in public processes [33]. The sections presenting the empirical material describe the different stakeholders' motives relating to actions concerning partnerships, forest protection, and institutionalization as well as their attitudes towards the government's capacity to institutionalize the studied partnership. The dominating motives are highlighted to exemplify different positions and common views among the key stakeholders. The content of these motives are then analyzed to establish a picture of shared and conflicting positions [34].

Semi-structured interviews with all the relevant actors (16 in total) were conducted during the spring of 2015. The sample included partners from the pilot phase of the Komet program and representatives of organizations involved in the present institutionalization phase: the Swedish Environmental Protection Agency (SEPA), the Swedish Forest Agency (SFA), two regional Forest Agency District Offices (in Västerbotten and Västra Götaland), the Federation of Swedish Farmers (FSF), three County Administrative Boards (Västerbotten, Skåne and Västra Götaland), two forest owners' associations (Norra Skogsägarna and Södra Skogsägarna), the Swedish Forest Industries Federation, the World Wide Fund For Nature (the WWF resigned from its participation in the Komet program in 2013), and the Swedish Society for Nature Conservation (the SSNC resigned from its participation in the Komet program in 2014). The environmental organizations resigned partly due to lack of resources, their other motives for withdrawal will be explained in the results. The interviews lasted approximately forty to sixty minutes, were transcribed, and the respondents were given the opportunity to review and revise the transcripts.

\section{Results}

\subsection{Introduction}

Four distinct formal forest protection schemes exist in Sweden: national parks, nature reserves, woodland habitats, and Nature Conservation Agreements (NCAs). National parks and nature reserves are generally large areas, while woodland habitats and NCAs are smaller. An important difference of protection is that NCAs are not a permanent form of protection but are based on civil law, lasting for a maximum of 50 years. In contrast to the other three forms of protection, NCAs are therefore regarded as "voluntary". Once established, an NCA has a legal basis and is defined as a form of formal protection by the Swedish Forest Agency, albeit with a limited time frame [35]. Within the Komet program, the landowners initiate the protection rather than the authorities [6].

The evaluation of the Komet program stated that the program had enhanced collaboration between the relevant agencies and forest owners' associations, and that individual landowners' interest in forest protection had increased. In addition, the program's administrative costs were high compared to traditional formal protection. Based on the landowners' limited interest in the program, it was stated that the compensatory grants issued to landowners were insufficient. It was also assumed that a nationwide implementation would increase the length of the queue of landowners 
waiting for compensation. Despite these considerations and the stakeholders' divergent views, the government decided to implement a nationwide partnership program inspired by the Komet program. This expanded program was to be implemented alongside existing formal protection instruments, which involve work on site protection that is initiated by responsible agencies [6].

The following sections present the views of the key stakeholders on partnerships, forest protection, institutionalization, and the government's capacity to create the necessary conditions for the implementation of a nationwide forest protection partnership.

\subsection{Stakeholder Experiences of the Komet Program}

This section focuses on the interviewed key stakeholders' perceptions of the collaborative efforts that were made in the course of the Komet program's pilot phase in 2010-2014. The potential influence of these past experiences on the stakeholders' opinions concerning the institutionalization process is also explored.

The different state agencies-the SEPA, SFA and CABs-which were involved in the program at the national level, felt that their relationships had become strengthened. However, they had a dialogue also before the program was initiated relating to formal forest protection. The representatives of the forest owners' associations on the national committee felt that contact had enhanced their understanding of the agencies' interests. The representatives of the Skåne CAB, the SFA, and the forest owners' associations all considered the atmosphere in the reference group to have been empowering and felt that they were given enough time to work on the designated issues-as one representative put it, "... I am actually very positive. We went to all the meetings in the reference group, so we were a very open group, and that made us put a lot of time into it ... " (CAB officer, national level). In contrast, the regional-level representatives from CABs and Forest Agencies did not feel that they had sufficient time to develop relationships with their new partners. The forest owners' associations said that they wanted more influence over the management of formal protection regimes. Some of the forest owners' associations and the environmental organization World Wildlife Fund seem not to have accepted the SFA and SEPA's suggested directives for the new partnership and to perceive them as a compromise that erodes the Komet program's initial purpose.

Since the environmental organization WWF resigned from the Komet program in 2013, they did not have a comprehensive overview of the collaboration during the pilot period. The environmental organization Swedish Society for Nature Conservation (SSNC), however, found the collaboration within the reference group somewhat problematic, and saw the group as a forum in which the responsible agencies made decisions about the ongoing process during the pilot period. The SSNC's officer defined collaboration as: ". . a form of partnership where you agree on the goals and methods", and thought that they had never achieved this. In particular, the SSNC did not consider any deliberative process to have occurred; they felt that they were not heard and only obtained information about the program and its implications. Consequently, the SSNC representative experienced power asymmetries within the reference group. In addition, the environmental organizations emphasized that the Komet program's final results show that biodiversity values were not sufficiently protected. SSNC's officer argued that since the government is incapable of achieving its stated forest protection goals using 'traditional' methods, 'experimenting' with voluntary methods is inefficient and time-consuming. According to the same spokesperson, the present loss of forest biodiversity is so great that the government should focus the majority of its effort on protecting larger and more comprehensive areas. In contrast, both the responsible agencies and forest owners' associations considered the experiences from the pilot period to be worthy of further development because voluntary incentives can rebuild trust and deepen relationships with private landowners. Their position is that voluntary incentives may be more time-consuming but will have long-term benefits for forest protection. Nevertheless, some counties already have a large queue of landowners waiting for compensation. In the five areas where the program was piloted, there appeared to be a negative correlation between the number of 
landowners in the queue for compensation and non-participating landowners' interest in applying for the Komet program (as measured by the number of applications to enter the program).

To summarize, the stakeholders' views on the benefits of the Komet program varied considerably, leading to divergent views on how the pilot period functioned. As mentioned, past experiences can influence future collaborations because they are important determinants of partnership structure.

\subsection{The Motives of the Key Stakeholders for a Nationwide Implementation}

Given the stakeholders' divergent views on the success of the Komet pilot phase, the program's partnership arrangements were adjusted before it was expanded nationwide in 2015. This section discusses the motives of the interviewed key stakeholders relating to the process of institutionalization. The goal of developing a new partnership model to complement extant models was initially proposed by SEPA and SFA in their joint report entitled 'Formal protection of forest: Introduction of a complementary method'.

The officers of the SEPA and SFA who worked with the program at the national level between 2010-2014 emphasized that the new partnerships did not function in exactly the same way as those of the Komet program, and, as such, represented a compromise: "The government has been very clear that this is a complementary method to be used in conjunction with authority-initiated formal protection procedures. This implies that some prioritization must be made. No such prioritization appeared to be involved during the Komet period, so this is something new" (SEPA officer, national level). These officers proposed that public agencies' forest protection initiatives should generally be assigned the highest priority. However, if a landowner were to submit a high quality expression of interest in forest protection, this expression could also be prioritized. The SEPA and SFA also argued that because the partnership program was intended to be implemented on a nationwide basis, it would have to comply with existing forestry laws. The SFA's project leader concluded that this would impose higher quality requirements than were required under the Komet program, as well as minimum limits on the size of the protected areas-all to safeguard biodiversity concerns.

Although the environmental organizations agreed that collaboration with other forest partners must be improved, they feared that expanding the Komet program to the national level would not reliably protect forest biodiversity values. The SSNC's experience of not being fully included in the Komet program's reference group strengthened their opinion that the implementation of a similar forest program would not help in preserving biodiversity. The bottom-up approach was viewed, particularly by the SSNC, as inefficient in protecting valuable forests. Hence, they had decided to prioritize other forest protection projects. As Table 1 indicates, with smaller size and less permanent protection forms such as nature reserves dominating inside the program, this suggests that the potential quality of protection within the Komet program is generally inferior compared with protection under more traditional approaches. However, the forest owners' associations suggested that bottom-up approaches could bring other long-term benefits such as reduction of conflicts between different actors. Most regional-level public officers from Forest Agencies and CABs were concerned that under the new partnership model potential constraints on resources and time could lead to difficulties in deciding how to prioritize incoming forest parcels.

The forest owners' associations perceived the new partnerships as a way of bringing voluntary initiatives into the national system for formal protection, however, they felt that the new approach differed too much from the Komet pilot program. They feared that even in a Komet-inspired partnership, landowners might feel their voices did not carry enough weight, and that the decision to strictly adhere to forestry laws would risk creating " . . a diluted version of the Komet program ..." (FSF officer, regional level). On the other hand, the farmers' representative (including the major forest owners' associations) advocated for partnerships to be the main method for protecting forests rather than a complement to 'traditional' formal protection: " . . it cannot be voluntary but only when it suits them. It cannot be like that because then you will have it hanging above your head and then the voluntariness is not voluntary anymore ... " (FSF officer, regional level). 
To sum up, the key stakeholders have very different motives for formalizing partnerships. These differences must be acknowledged during the institutionalization phase to avoid eventual conflicts and the creation of power asymmetries. In particular, the environmental organization SSNC's experience of power asymmetries seem related to their skepticism towards the new partnership. However, ideology also seems to be playing a role in the way the nationwide partnership is being conceived.

\subsection{The Statements Found in the Referrals on Institutionalization}

Studies of the stakeholders' formal motives for institutionalizing the partnership showed that the involved stakeholders take different stances on several aspects of the proposals made by the SEPA and SFA.

The two environmental organizations stated that the SEPA and SFA's expectations for the forest industry to serve as funders and information providers are inappropriate in a public proposal. They argued that the forest industry should not play a major role in the development of voluntary agreements for protecting forests, which was indicated in the referral composed by the SEPA and SFA. More importantly, they were skeptical about the proposal's likely outcome in terms of forest protection, and argue that protection should involve systematic mapping of forests with high biodiversity value. They feared that only less valuable forest areas would be chosen for protection if the protection were to be initiated by the landowners. Referring to the Komet program's results in terms of protected forest confirms their suspicions. They therefore proposed an alternative forest protection strategy developed by their own forest advisors.

In contrast to the environmental organizations' extensive texts, the Forest Industries formulated a minor statement saying that they were looking forward to working with the new system. The Federation of Swedish Farmers' referral (which included contributions from the involved forest owners' associations) was also positive about the introduction of complementary partnerships. They suggested that, with the exception of already initiated top-down protection processes, initiatives from landowners should be prioritized. However, they also contend that the proposal did not provide explicit guidance on how landowners' initiatives should be prioritized and incorporated into existing regulations. Their referral concludes by noting that social values should be incorporated into the new procedures.

Of twenty-one CABs in Sweden, nineteen submitted a referral. These referrals clearly reflected a degree of insecurity among the CABs concerning the use of nationwide partnerships, linked to a common fear that the CABs would be at risk of making promises to landowners that they would be unable to keep due to a lack of resources. Despite these concerns, the majority of the CABs supported new efforts to inform landowners, thereby attempting to increase their interest in protection. Those CABs that had been involved in the Komet program tended to be more positive about the introduction of a complementary partnership. Others placed more emphasis on potential drawbacks. For instance, the Örebro CAB argued that a complementary partnership would not function properly because there was already little interest among landowners in implementing 'traditional' NCAs. A majority of the regional units of the Forest Agency expressed similar concerns, namely that the partnerships were not compatible with their strategies for protecting forests, although they emphasized support for landowner initiatives. Their concerns were related to a fear of decreasing resources for protecting forests with high biodiversity. The CABs were also skeptical about the outcome in terms of forest protection, stemming from concerns about the constraints on the forest protection budget.

The stakeholders' referrals thus show that there are several different views on partnerships, what a partnership should be used for and how. In particular, the environmental organizations were skeptical of the use of partnerships. This primarily related to their belief that partnerships are generally inferior to top-down strategies for forest protection due to their lesser potential in use of strategic planning for nature protection. Of the involved agencies at a regional level those that participated during the pilot period were more positive than those that had not. Those agencies that had not previously participated were particularly concerned about the lack of resources to support voluntary agreements. The outcome 
of the pilot period was mentioned as another reason for not implementing a nationwide partnership because it indicated that bottom-up partnerships were less efficient than top-down protection forms. Still, the forest owners' associations and forest industry representatives were positive and proposed that voluntary schemes should be further developed for protection of private forest areas.

\subsection{Views on Government Capacity to Manage Partnership Institutionalization, and Requirements for Implementation}

Key stakeholders' were asked about their opinions concerning the government's capacity to establish the necessary conditions for successful partnerships. The interviewed partners wanted the government's leadership capacity to be developed. A perceived lack of leadership concerning how the directives were formulated was considered to have influenced the structure of the partnerships. The environmental organizations wanted more guidance in the directives and that the responsible agencies (the SFA and SEPA) would take the lead in the implementation through the allocation of resources at the regional level. The regional agency officers from the Forest Agency district offices and CABs suggested that the directives needed to be more extensively adapted to the conditions in each county. Both the SEPA and SFA, however, emphasized that they were obliged to adhere to the government's directives despite their perceived lack of resources for forest protection. Thus, they expressed high dependency on the forest industry's engagement in the partnership. However, the northern forest owners' association argued that the government should take more responsibility in terms of governing and resources for the voluntary protection regime to achieve its full potential.

The environmental organizations in particular thought that the decision to implement a nationwide partnership had been taken too quickly. They questioned the government's ability to manage voluntary protection. The WWF's officer perceived that the government's intentions had profoundly changed under the management from the SFA and SEPA. However, the SFA's project leader emphasized that the partnerships were originally intended to be steered by the SEPA and SFA together and that the government therefore expected them to complete this work.

The representatives from the forest owners' associations argued that a political change is needed before voluntary practices will have a role to play in formal forest protection: " .. politicians must give a higher status to voluntary protection, in which landowners also have incentives to manage forests for biodiversity as well as for production ..." (FSF officer, national level). This would entail major changes in the national strategy to better support voluntary protection. In contrast, the environmental organizations, however, demanded increased mandatory protection. At the regional level, some public officers agreed on this matter and found mandatory regulation efficient, even though this presented a risk that "you run over people ... but it should be considered a national interest to protect forests just as it is to build a public road ... (SFA officer, regional level). These officers claimed that voluntary approaches are better suited for fragmented landscape types. At the same time, they expressed a willingness to incorporate social values, which they assumed would give an expanded protection agenda. The SFA and SSNC officers argued that the inclusion of social values is not new and, as such, is not an innovative practice. They referred to outdoor activities as a common reason for protection that already incorporates social values. The representatives of the environmental organizations and the SFA at both the national and regional levels, however, stated that social values should not be the dominating theme in forest protection.

The analysis of the interviews revealed three primary concerns: time, leadership capacity, and resources. Most of the interviewed stakeholders, particularly on the regional levels, felt that they needed more time to reflect and think through the objectives associated with the implementation of a complementary partnership. They also felt that they already had a tight schedule to follow. Therefore, the idea of incorporating a time-consuming partnership into their existing strategies created feelings of stress.

Several of the interviewed key stakeholders asked for clearer directions from the government. Lack of leadership could potentially undermine the government's capacity (and that of its responsible 
agencies) to make compromises that would satisfy different interests. More importantly, ambiguous leadership undermines the government's capacity to create the initial conditions for institutionalization. There is thus a need for synchronization at the administrative level since collaborative efforts need synchronization [36] between the national and regional agencies. At the regional level, the involved stakeholders asked for context-based guidelines since the forest types suitable for protection and the queue of landowners waiting for compensation tend to vary between counties. Hence, a lack of coordination will have particularly strong effects on the regional districts where the partnerships are ultimately implemented.

The resource dilemma relates to leadership capacity since it is the government that allocates the financial resources to protect forests. However, the budget does not seem to be keeping pace with the new working methods for protecting forests. Despite their generally positive attitudes to the partnership scheme, both the SEPA and SFA were very conscious of the lack of resources and queues of waiting landowners. Paradoxically, the lack of resources was initially used as an argument for a need to collaborate with the forest industry. This position disturbed the environmental organizations since they found it quite controversial for public agencies to form alliances with the forest industry to protect forests rather than securing public funding to this end.

\section{Discussion}

\subsection{Previous Experience Matters}

Most of the interviewed key stakeholders seemed to have established well-functioning relationships with each other within the Komet program. This is particularly true for the responsible agencies (i.e., the SEPA, SFA, and the Skåne CAB). However, how they should continue to develop and eventually formalize these relationships did not appear to have been discussed at any great length. This is exemplified by the lack of agreement regarding the extent to which the Komet program could be considered a deliberative process. Some of the stakeholders, particular from the environmental organizations and regional agencies, are quite skeptical about the program's efficiency as a tool for forest protection. They view the outcome, as shown in Table 1, as disappointing. The lack of agreement during the pilot period seemed to also affect the present institutionalization process. For instance, some of the interviewed stakeholders' skeptical attitudes are linked to a perceived lack of resources [16]. Furthermore, several of the interviewed stakeholders expressed disbelief regarding the new partnerships' role in spurring formal protection.

To summarize, the results show the importance of considering the key stakeholders' experiences of the pilot phase. The interview responses confirmed that past experiences influenced the stakeholders' motives relating to the institutionalization process $[17,18]$.

\subsection{Challenging to Find a Compromise between the Different Motives}

The SEPA and SFA found it challenging to strike compromises between the different key stakeholders' motives regarding a nationwide implementation. The environmental organizations had mixed motives relating to the institutionalization process because from their perspective the pilot phase had been disappointing. Even if they were positive about working with new stakeholders, they were skeptical about the outcome in terms of forest protection. They believed that environmentally valuable forests should be protected using mandatory regulation to counteract the trend of increasing biodiversity loss. However, their criticisms were not based exclusively on past experiences-they also expressed a general critique of the partnerships' bottom-up character [19]. Hence, they thus also expressed ideological motives for claiming that a nationwide partnership could not be effective. Several of the regional $\mathrm{CABs}$ and forest agencies also agreed that the most efficient strategy for protecting forests is to use regulatory tools.

The motives of the forest owners' associations and forest industry representatives were based on the landowners' right to ownership. These stakeholders supported bottom-up strategies and wanted a 
major change in the forest protection agenda that would turn voluntary protection into the dominant strategy. They stressed the importance to account for both social and environmental values before protecting forests and that such inclusion of values other than preservation of biodiversity reflects a willingness to change the traditional image of forest protection.

The motives tend to be influenced by a combination of past experiences and values or ideologies such as ecocentric or anthropocentric views. If some of the involved stakeholders have negative past experiences together with a critique of bottom-up strategies, these motives may present difficult obstacles to the initiation of an institutionalization process. If landowners' actions are actively supported for preserving specific forms of biodiversity, a more permanent transformation of new ideas in forest protection may develop such as in the Finnish METSO program [5].

\subsection{Lack of Governmental Capacity Affects the Final Implementation Phase}

Several of the interview responses and referrals also identified the government's lack of capacity to create the conditions necessary for successful institutionalization as a problem [26]. Most of the interviewed stakeholders, particular on the regional levels, mentioned a lack of time to work on new strategies. This issue must be addressed because the development of new working methods is time-consuming, especially when relationships must be established or modified.

The primary dilemmas highlighted in the referral round relating to the proposals of the SFA and SEPA were the lack of resources and the queue of landowners waiting for compensation. There was also a perception that the available resources were not fairly distributed because the queue of landowners differed among counties. More resources are needed before the public agencies will consider using a partnership-based approach [16]. The SEPA and SFA used the lack of resources as an argument for the need to invite forest industry to act as a collaborative funder. However, the desire to seek help from forest industries for forest protection was regarded with suspicion by the environmental organizations.

The emphasis placed on the roles of landowners in the referrals from the regional CABs and forest agencies depended on these regional agencies' past experiences with collaborative projects [29]. In general, regional agencies tended to be more positive towards the implementation of partnerships if they had experience of working in collaborative projects [16,29]. This was particularly true for those regional agencies that had participated in the pilot phase.

The involved actors asked for leadership [26,29], but from different levels. The SEPA and SFA's officers, at the national level, emphasized that they had to follow the directives from the government. The forest owners' associations demanded increased involvement from the government due to its responsibility for resource distribution. The environmental organizations urged the responsible agencies (the SEPA and SFA) to take direct responsibility for managing forest protection. Their opinion was that the SEPA and SFA should argue more forcefully for an increased allocation of resources rather than just accepting those given by the government. The regional agencies wanted the suggested directives to be adapted on a county-by-county basis to reflect each county's unique conditions. Some of these agencies considered partnership implementation to be unnecessary because they already had a well-developed dialogue with private landowners. Overall, most of the interviewed key stakeholders expressed frustration about the government's lack of capacity in its role of controlling and setting guidelines [25]. Hence, both the government and the responsible agencies need to exhibit a capacity for leadership $[27,28]$.

The major dilemma regarding the government's capacity seems to lie in its inability to steer through different levels of governance (e.g., the national and regional levels) [36,37]. This is problematic because collaborative efforts require synchronization [37]. The partnership concept was initially intended to permit both traditional and new stakeholders to discuss and engage $[8,9]$ in the development of formal protection. However, the newly invited stakeholders perceived that they had not fully developed their relationships with the others. They also experienced power asymmetries [11,12], which related to a feeling of not being fully included in the partnering process.

Overall, the government did not seem well-adjusted to the present partnership arrangement [23]. The establishment of a rule system to steer the implementation has major weaknesses. Since the wider institutional settings were not fully developed for large scale implementation, this affected the regional 
agencies' ability to address practical challenges using voluntary incentives. These obstacles imply that the scope for using partnerships to change the societal structures of forest protection was limited. If partnerships are to "change the political order" [11], they must be allocated more leadership capacity, time, and resources so that the necessary relationships can be organized on the national level.

Another dilemma is the Swedish policy tradition of top-down protection, which risks obstructing an institutionalization process. Countries with traditions of voluntary protection, such as Norway and Austria, may be more adapted to incorporate partnerships into their governance systems [38,39]. Hence, the introduction of partnerships in Swedish forest policy requires considerable time, and allocation of new resources into to the relevant agencies.

The key stakeholders clearly did not have a common perception of the Komet program's final results. Their disagreements were further reflected in the subsequent institutionalization process. Past experiences must be considered to enable the implementation of partnerships [29]. Otherwise, the use of partnerships might be characterized by a high risk of perceived power asymmetries [11], which implies that some invited stakeholders might consider their voices as unheard. Merely inviting new stakeholders from different sectors is not enough to promote collaboration. They need to feel that opinions are recognized and that the partnership supports their interests [11]. The involved key stakeholders' motives for participating in the process varied widely, even if they expressed the same goal of protecting forests. A lack of information about the Komet program's objectives during the pilot period may partially explain the reluctance of the involved stakeholders to compromise their interests. The questioning of the program's legitimacy, particularly by the environmental organizations, probably also contributed to the skepticism of some key stakeholders.

The results indicate an insecurity amongst the regional agencies regarding the nationwide implementation of the program. They perceive themselves as resource-poor and therefore question the partnership's overall objective. Therefore, a major change in the national strategy for formal forest protection would be required before partnerships can be added to the existing formal protection goals. This could, for instance, imply that the national strategy would recognize partnerships as being as highly prioritized as 'traditional' protection methods. Such a development might open up new discussions on whose values should be recognized in forest protection. The use of partnership approaches can facilitate the protection of forest areas but with another focus than traditional protection of biodiversity values. Incorporation of 'new' values might widen the protection agenda and make landowners more willing to voluntary protection.

The institutionalization of a nationwide partnership represents an attempt by the government to make private landowners more interested to protect forests. However, there is still a lack of acceptance for this approach among some key stakeholders. Government action is still required to set rules that will define the workings of new exchanges for forest protection [23]. This study shows that past experiences and the motives of the involved actors must be considered carefully before institutionalization can develop.

\section{Conclusions}

Partnerships can contribute to the delivery of public goods, however, they cannot be organized in the same way as a program with top-down steering. In the case of forest protection, top-down steering using mandatory tools runs the risk of creating opposition among private landowners as well as central stakeholders from the forest sector. Because governments depend on the actions of private landowners to achieve their forest protection goals, the use of top-down steering that alienates landowners can have negative effects. Partnerships can facilitate collaboration between different stakeholders even if they do not necessarily give every involved actor exactly what they want. Moreover, the use of partnership approaches can enable the protection of forest areas that were not previously registered as valuable. The responsible agencies can thus achieve an increase in the quantity of protected forest land. However, a disadvantage of the partnership approach is that the areas selected for protection in landowners' expressions of interest are unlikely to be chosen only on the basis of quality (i.e., biodiversity and 
importance to the local ecosystem/community). Furthermore they tend to be smaller compared to formal forms of protection which may be a disadvantage given what is to be protected (see Table 1). As shown in Table 1, the interest for different forms of protection differ inside and outside the Komet program, with smaller size and less permanent protection forms such as nature reserves dominating inside the program, suggesting that the potential quality of such protection is generally inferior compared with the traditional forms of protection. In addition, the number of interest applications within the program is also quite small (about $7 \%$ of all applications during this period).

This study examined a case in which the government had chosen to make a trade-off by implementing nationwide partnerships despite defects identified in a pilot program. Several factors were identified as being important for the institutionalization of this new approach to forest protection; in particular, that the process must work for most of the involved stakeholders. However, the necessary conditions for institutionalization do not yet seem to have been established. Specifically, the government did not allocate enough resources, and has not shown sufficient leadership. The responsible agencies are further criticized for not being able to deliver in terms of their leadership capacity. These shortcomings in the authorities' ability to implement could potentially undermine the long-term objectives of a nationwide implementation (i.e., to increase private landowners' interest in forest protection and to rebuild relationships with forest stakeholders). Overall, the results are related to (1) past experiences with collaborative efforts; (2) motives influenced by beliefs that partnerships are inferior to top-down strategies for forest protection or contrary viewpoints; and (3) lack of leadership capacity. Those results are generalizable outside of Sweden, where similar experiences can be found. However, Sweden's tradition of top-down protection indicates that the current transformation of forest protection to use bottom-up approaches may take time to develop compared to, for example, Norway, where voluntary measures are more commonly used.

On the one hand, there is good reason to believe that if the necessary conditions can be established, partnership arrangements could represent a viable compromise that would combine private and public interests in forest protection. Such arrangements are needed to deliver collective goods. On the other hand, this case study illustrates the difficulties in reconciling private and public interests since representatives of forest owners promoted private interests in combination with anthropocentric values, and representatives of environmental organizations promoted public interests based on ecocentric values, and the government was caught in the middle. The Swedish government's lack of capacity to mitigate between these opposing views was revealed as the necessity of implementing a nationwide partnership was questioned and interpreted differently among involved stakeholders. To be successful, a shift away from 'traditional' views on forest protection seems to be needed to fully develop a partnership approach to forest protection. However, the government also needs to allocate more resources to clarify the purpose of the partnering process, to clarify the policy recommendations for the use of partnerships, and to be able to ensure that the quality of forest protection is not reduced compared to traditional protection.

Acknowledgments: This work was supported by Swedish Research Council Formas (251-2011-117).

Conflicts of Interest: The author declares no conflict of interest.

\section{Abbreviations}

The following abbreviations are used in this manuscript:

$\begin{array}{ll}\text { NCA } & \text { Nature Conservation Agreements } \\ \text { SEPA } & \text { Swedish Environmental Protection Agency } \\ \text { SFA } & \text { Swedish Forest Agency } \\ \text { CAB } & \text { County Administrative Board } \\ \text { WWF } & \text { World Wide Fund for Nature } \\ \text { SSNC } & \text { Swedish Society for Nature Conservation } \\ \text { FSF } & \text { Federation of Swedish Farmers }\end{array}$




\section{References}

1. Lindstad, B.H.; Solberg, B. Influences of international forest policy processes on national forest policies in Finland, Norway and Sweden. Scand. J. For. Res. 2012, 27, 210-220. [CrossRef]

2. Swedish Gov. Bill. Regeringens Proposition 2013/14:141; Ministry of Government: Stockholm, Sweden, 2013. (In Swedish)

3. Swedish Gov. Bill. Hållbart skydd av naturområden, Proposition 2008/09:214; Ministry of Government: Stockholm, Sweden, 2008. (In Swedish)

4. Swedish Environmental Protection Agency; Swedish Forest Agency. Nationell strategi för Formellt skydd av skog; Rapport CM-gruppen: Bromma, Sweden, 2005. (In Swedish).

5. Vainio, A.; Paloniemi, R. Adapting to the gender order: Voluntary conservation by forest owners in Finland. Land Use Policy 2013, 35, 247-256. [CrossRef]

6. Swedish Environmental Protection Agency; Swedish Forest Agency; County Administrative Board Skåne. Kometprogrammet slutrapport 2010-2014. Available online: http://www.skogsstyrelsen.se/Myndigheten/ Projekt/Avslutade-projekt/Ovriga-projekt/Kometprogrammet/Dokumentation/ (accessed on 17 April 2015). (In Swedish)

7. Ångman, E. Feelings and Fellings-Exploring the Process of Communication in Forest Management Conflicts. In Academic Dissertation; Faculty of Natural Resources and Agricultural Sciences Department of Urban and Rural Development: Uppsala, Sweden, 2012.

8. Lantbrukets affärstidning. Available online: http://www.atl.nu/synpunkten/kometprogrammet-har-f-rndrat-attityderna (accessed on 17 April 2015). (In Swedish)

9. Naturskyddsföreningen remissvar; Skogsstyrelsen; Naturvårdsverket. Formellt skydd av skog-Införande av en kompletterande arbetsmetod. Available online: http:/ /www.naturskyddsforeningen.se/sites/default/ files/dokument-media/remissvar/komet-remissvar-naturskyddsf\%C3\%B6r\%20_jan2015.pdf (accessed on 19 January 2015). (In Swedish)

10. Hodge, A.G.; Greve, C. Public-Private Partnerships: An International Performance Review. Public Adm. Rev. 2007, 67, 545-558. [CrossRef]

11. Glasbergen, P. Understanding partnerships for sustainable development analytically: The ladder of partnership activity as a methodological tool. Environ. Policy Govern. 2011, 21, 1-13. [CrossRef]

12. Bitzer, V. Partnering for Change in Chains: On the Capacity of Partnerships to Promote Sustainable Change in Global Agricultural Commodity Chains; Academic Dissertation, Utrecht University Repository: Utrecht, The Netherlands, 2011.

13. Biermann, F. Earth system governance' as a crosscutting theme of global change research. Glob. Environ. Chang. 2007, 17, 326-337. [CrossRef]

14. Hardy, C.; Lawrence, T.B.; Phillips, N. Swimming with sharks: Creating strategic change through multi-sector collaboration. Int. J. Strateg. Chang. Manag. 2006, 1, 113-126. [CrossRef]

15. Barnett, M.L. Stakeholder influence capacity and the variability of financial returns to corporate social responsibility. Acad. Manag. Rev. 2007, 32, 794-816. [CrossRef]

16. Seitanidi, M.M.; Austin, J.E. Collaborative Value Creation A Review of Partnering Between Nonprofits and Businesses. Part 2: Partnership Processes and Outcomes. Nonprofit. Volunt. Sect. Q. 2012, 41, 929-968. [CrossRef]

17. Jones, C.; Hesterly, W.S.; Borgatti, S.P. A General Theory of Network Governance: Exchange Conditions and Social Mechanisms. Acad. Manag. Rev. 1997, 22, 911-945. [CrossRef]

18. Ring, P.S.; van de Ven, A.H. Developmental Processes of Cooperative Interorganizational Relationships. Acad. Manag. Rev. 1994, 19, 90-114. [CrossRef]

19. Sténs, A.; Bjärstig, T.; Nordström, E.M.; Sandström, C.; Fries, C.; Johansson, J. In the eye of the stakeholder: The challenges of governing social forest values. Ambio 2016, 45, 87-99. [CrossRef] [PubMed]

20. Verhoest, K.; Petersen Helby, O.H.; Scherrer, W.; Murwantara Soecipto, R. How Do Governments Support the Development of Public Private Partnerships? Measuring and Comparing PPP Governmental Support in 20 European Countries? Transp. Rev. 2015, 35, 118-139. [CrossRef]

21. Phung Dang, T.K.; Visseren-Hamakers, I.J.; Arts, B. A framework for assessing governance capacity: An illustration from Vietnam's forestry reforms. Environ. Plan. C Gov. Policy 2015. [CrossRef] 
22. Klijn, E.H.; Teisman, G.R. Institutional and strategic barriers to Public_Private Partnership: An analysis of Dutch cases. Public Money Manag. 2003. [CrossRef]

23. Börzel, T.A.; Risse, T. Public-Private Partnerships: Effective and Legitimate Tools of International Governance? In Complex Sovereignty: On the Reconstitution of Political Authority in the 21st Century; Grande, E., Pauly Louis, W., Eds.; University of Toronto Press: Toronto, ON, Canada, 2005.

24. Bäckstrand, K. Multi-stakeholder partnerships for sustainable development: Rethinking legitimacy, accountability and effectiveness. Environ. Policy Gov. 2006, 16, 290-306. [CrossRef]

25. Nemes, G.; High, C.; Augustyn, A. Beyond New Rural Paradigm: Project State and Collective Reflexive Agency. In Territorial Cohesion in Rural Europe: The Relational Turn in Rural Development; Copus, A., de Lima, P., Eds.; Routledge: London, UK, 2014.

26. Emerson, K.; Nabatchi, T.; Balogh, S. An integrative framework for collaborative governance. J. Public Adm. Res. 2011, 22, 1-29. [CrossRef]

27. Agranoff, R.; McGuire, M. Multinetwork management: Collaboration and the hollow state in local economic policy. J. Public Adm. Res. Theor. 1998, 8, 67-91. [CrossRef]

28. Bryson, J.M.; Crosby, B.C. Failing into cross-sector collaboration successfully. In Big Ideas in Collaborative Public Management; Bingham, L.B., O’Leary, R., Eds.; M.E. Sharpe: Armonk, NY, USA, 2008.

29. Ansell, C.; Gash, A. Collaborative Governance in Theory and Practice. J. Public Adm. Res. Theor. 2008, 18, 543-571. [CrossRef]

30. Selin, S.; Chavez, D. Developing an evolutionary tourism partnership model. Ann. Tour. Res. 1995, 22, 844-856. [CrossRef]

31. Satterfield, T. In Search of Value Literacy: Suggestions for the Elicitation of Environmental Values. Environ. Value 2001, 10, 331-359. [CrossRef]

32. Van Eemeren, F.H.; Grootendorst, R.; Snoeck Henkemans, F. Argumentation-Analysis, Evaluation, Presentation; Lawrence Erlbaum Associates Inc. Publishers: Mahwah, NJ, USA, 2002.

33. Fisher, F.; Forrester, J. The Argumentative Turn in Policy Analysis and Planning; Duke University Press: Durham, NC, USA, 1993.

34. Rantala, T.; Primmer, E. Value positions based on forest policy stakeholders' rhetoric in Finland. Environ. Sci. Policy 2003, 6, 205-216. [CrossRef]

35. Beland-Lindahl, K. Frame Analysis, Place Perceptions, and the Politics of Natural Resource Management. Exploring a Forest Policy Controversy in Sweden. Ph.D. Thesis, Swedish University of Agricultural Sciences, Uppsala, Sweden, 2008.

36. Lange, P.; Driessen, P.J.; Sauer, A.; Bornemann, B.; Burger, P. Governing Towards Sustainability-Conceptualizing Modes of Governance. J. Environ. Policy Plan. 2013, 15, 403-425. [CrossRef]

37. Marin, A.; Berkes, F. Network approach for understanding small scale fisheries governance: The case of the Chilean coastal co-management system. Mar. Policy 2010, 34, 851-858. [CrossRef]

38. Fauchald, O.; Gulbrandsen, L.; Zachrisson, A. Internationalization of protected areas in Norway and Sweden: Examining pathways of influence in similar countries. Int. J. Biodivers. Ecosyst. Manag. 2014, 10, $240-252$. [CrossRef]

39. Frank, G.; Muller, F. Voluntary approaches in protection of forests in Austria. Environ. Sci. Policy 2003, 6, 261-269. [CrossRef]

(C) 2016 by the author; licensee MDPI, Basel, Switzerland. This article is an open access article distributed under the terms and conditions of the Creative Commons Attribution (CC-BY) license (http://creativecommons.org/licenses/by/4.0/). 